\title{
(6) OPEN ACCESS \\ Elevated inflammatory biomarkers during unemployment: modification by age and country in the UK
}

\author{
Amanda Hughes, ${ }^{1}$ Anne McMunn, ${ }^{1}$ Mel Bartley, ${ }^{1}$ Meena Kumari ${ }^{1}{ }^{1}$
}

\begin{abstract}
- Additional material is published online only. To view please visit the journal online (http://dx.doi.org/10.1136/jech2014-204404).

${ }^{1}$ Department of Epidemiology and Public Health, University College London, London, UK ${ }^{2}$ Institute for Social and Economic Research, University of Essex, Colchester, UK
\end{abstract}

\section{Correspondence to} Amanda Hughes Department of Epidemiology and Public Health, University College London, 1-19 Torrington Place, London WC1E 6BT, UK; a.hughes.11@ucl.ac.uk

Received 16 May 2014 Revised 1 October 2014 Accepted 25 January 2015 Published Online First 19 February 2015

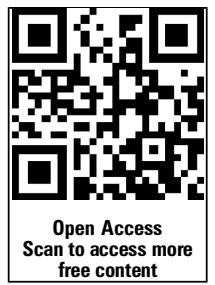

CrossMark

To cite: Hughes $A$, McMunn A, Bartley M, et al. J Epidemiol Community Health 2015:69:673-679.

\section{ABSTRACT}

Background There is raised risk of mortality following unemployment, and reviews have consistently found worse psychological health among the unemployed. Inflammation is increasingly implicated as a mediating factor relating stress to physical disease and is strongly linked to depression. Inflammation may, therefore, be implicated in processes associated with excess mortality and morbidity during unemployment. This study examined associations of unemployment with inflammatory markers among working-age men and women from England and Scotland.

Methods Cross-sectional analyses using data from the Health Survey for England and the Scottish Health Survey collected between 1998 and 2010. Systemic

inflammation was indexed by serum concentrations of $C$ reactive protein (CRP) and fibrinogen, and compared between participants currently employed/self-employed, currently unemployed and other groups.

Results CRP, fibrinogen and odds of CRP $>3 \mathrm{mg} / \mathrm{L}$ were all significantly raised for the unemployed, as compared to the employed participants (eg, OR for CRP $>3 \mathrm{mg} / \mathrm{L}=1.43, \mathrm{Cl} 1.15$ to $1.78 \mathrm{~N}=23$ 025), following adjustment for age, gender, occupational social class, housing tenure, smoking, alcohol consumption, body mass index, long-term illness and depressive/anxiety symptoms. Strengths of associations varied considerably by both age and country/region, with effects mainly driven by participants aged $\geq 48$ and participants from Scotland, which had comparatively high unemployment during this time.

Conclusions Current unemployment is associated with elevated inflammatory markers using data from two large-scale, nationally representative UK studies. Effect modification by age suggests inflammation may be particularly involved in processes leading to ill-health among the older unemployed. Country/regional effects may suggest the relationship of unemployment with inflammation is strongly influenced by contextual factors, and/or reflect life course accumulation processes.

\section{INTRODUCTION}

There is raised risk of mortality following unemployment ${ }^{1-3}$ and reviews have consistently found worse psychological health among the unemployed. ${ }^{4-6}$ Unemployment is a stressful life event, often involving loss not only of financial resources but psychosocial assets, such as time structure, status and social support. ${ }^{7}$ The inflammatory response occurs in response to infection or injury, where it helps to fight infection and repair damaged tissue, ${ }^{8}$ but can also occur for extended periods of time in the absence of infection or injury. Such 'systemic' inflammation is increasingly implicated as a mediating factor relating stress to cardiovascular disease ${ }^{9}$ and is strongly linked to depression. ${ }^{10}$ It is, therefore, plausible that inflammatory markers may be elevated in the unemployed, and reflect processes associated with the excess morbidity and mortality in this group. To our knowledge, two small-scale studies have examined associations of unemployment with inflammatory markers. We explored this association in a large data set of 23025 participants from the Health Survey for England (HSE) and Scottish Health Survey (SHeS), allowing for a wide range of potential confounders and mediators to be explored.

\section{METHODS}

\section{Participants}

The HSE and the SHeS are annual government surveys, each comprising a new sample every year, with core samples nationally representative of residents with private addresses. ${ }^{11} 12$ Each has a stratified two-stage sampling design, with households selected from primary sampling units. ${ }^{13}$ This analysis was restricted to core-sample participants of working age, defined as 16-64 last birthday.

Surveys consisted of a face-to-face interview followed by a nurse visit during which clinical measurements were taken, including serum $\mathrm{C}$ reactive protein (CRP) and fibrinogen, both markers of systemic inflammation. Data was aggregated from nine HSE and SHeS surveys in which CRP and fibrinogen measurements were taken for the core sample: HSE 1998, 1999, 2003, 2006 and 2009, and SHeS 2003, 2008, 2009 and 2010. From HSE 1999 and from the 2008 SHeS only a subsample of core sample adults were targeted for a nurse visit; so only these participants had measurements of CRP and fibrinogen. Observations from SHeS 2011 were not used, because introduction of a different CRP analyser resulted in measured CRP concentrations on average $15 \mathrm{mmol} / \mathrm{L}$ higher, leading to concerns about consistency. ${ }^{14}$

The initial sample comprised all core sample working-age adults from nine surveys targeted for a blood sample ( $\mathrm{N}=49$ 385). Of these, 43129 (87.3\%) consented to a nurse visit but only 30103 (61\%) consented to a blood sample. Problems in taking samples, laboratory problems with samples obtained, and nonmeasurement of fibrinogen for participants taking fibrates resulted in $27366 \mathrm{CRP}$ measurements and 24551 fibrinogen measurements.

Participants with CRP $>10 \mathrm{mg} / \mathrm{L}$ were excluded from CRP $(\mathrm{N}=1453)$ and fibrinogen analyses 
$(\mathrm{N}=1237)$ since this is considered evidence of current infection, rather than chronic processes. ${ }^{15}$ Of remaining observations, only 25 participants were missing employment status, but a further 2863 and 2568 participants were excluded due to missing covariates (mostly for body mass index, BMI, occupational social class and General Health Questionnaire (GHQ-12) score, missingness of 5.3\%, 3.6\% and 3\%, respectively, in CRP analyses). The final complete-case sample sizes were 23025 for CRP models, and 20724 for fibrinogen models.

\section{Measures}

Current employment status was assessed by questionnaire. Using the International Labour Organisation definition, we considered participants unemployed if they were without work and seeking work, or waiting to take up work. ${ }^{16}$ The baseline group in all analyses was participants in paid employment or selfemployment. Participants out of the labour force, due to sickness/disability or otherwise economically inactive (including homemakers, the retired, full-time students, participants in government training or doing unpaid work), were analysed separately. Participants who were unemployed but temporarily prevented from seeking work due to illness were included with the sick/disabled group.

In all surveys, serum CRP concentrations were analysed by the Biochemistry Department of the Royal Victoria Infirmary, Newcastle, using the $\mathrm{N}$ Latex CRP mono immunoassay on the Behring Nephelometer II Analyser. ${ }^{17}$ Imprecision at the low end of the analytical range results in a coefficient of variation of $<6 \%$ for this analyser. ${ }^{13}$ The limit of detection was $0.1 \mathrm{mg} / \mathrm{L}$.

Fibrinogen was analysed at the Royal Victoria Infirmary Haematology Department using a modified Clauss thrombin clotting method. The Organon Teknika MDA 180 analyser was used until HSE $2006^{18-21}$ when the Auto Coagulation lab (TOP) CTS analyser was introduced. ${ }^{13} 22-25$ A correlation of 0.96 indicates results from the two analysers are comparable. ${ }^{25}$ The limit of detection was $0.2 \mathrm{~g}$. Fibrinogen was not measured for participants taking drugs known to affect fibrinogen. Mean values of CRP and fibrinogen differed between surveys (see online supplementary appendix A).

All covariates except BMI were assessed by questionnaire. Socioeconomic position was indexed by occupational social class (Registrar General's Social Classification) from current or most recent employment, and housing tenure (classified as owns home outright, buying with a mortgage or loan or renting).

Smoking was categorised as never smoker, ex-smoker, current $(<10 /$ day), current (10-19/day) and current $(20+/$ day $)$. Alcohol intake was assessed by frequency of drinking occasions in the past year (every couple of months or less, 1-2 times per month, 1-2 times per week, 3-4 times per week, 5+ times per week or never). Height and weight were assessed by the nurse and BMI calculated, with WHO BMI categories $(<18.5,18.5-24.99$, $25.0-29.99,30+)$ used as measure of adiposity.

Long-term illness (mental or physical) was categorised as none, limiting and non-limiting. Total GHQ-12 score (dichotomised using the standard cut-off of $4+$ ) was included to account for depressive/anxiety symptoms. Non-steroidal anti-inflammatory drugs, systemic corticosteroids, corticosteroid injections, lipid-lowering drugs, $\beta$-blockers, diclofenac sodium for gout and aspirin or ibuprofen as an analgesic or antiplatelet were classified as medications that would influence inflammatory marker levels.

\section{Data analysis}

Multivariate linear regression was used to examine associations of unemployment with serum concentrations of CRP and fibrinogen (both log-transformed), and multivariate logistic regression to investigate associations of unemployment with odds of raised CRP, defined as $>3 \mathrm{mg} / \mathrm{L}$ - the standard cut-off in CRP analyses in recognition of the clinically significant increase in cardiovascular risk past this point. $^{26}$ All analyses used STATA's svyset command to account for clustering in the primary sampling unit.

Country and year were included as covariates, with 2003 (when large numbers of observations were collected in both countries) as baseline. Since only 166 usable observations came from HSE 1999, this was merged with HSE 1998.

Effect modification by gender and age were considered, since studies have indicated associations of unemployment with ill-health may be greater for younger people ${ }^{1}$ and men. ${ }^{6}$ To investigate age modifications, the sample was split into three equal-width age bands, corresponding to early career (16-31), mid-career (32-47) and late-career (48-64) participants. Within each band, age in years was adjusted for.

\section{Sensitivity analyses}

To investigate whether bias could have resulted from conducting a complete-case analysis, we compared age-adjusted, genderadjusted, country-adjusted and year-adjusted associations between unemployment and inflammatory markers in participants lacking covariate data and other participants. In total $12.7 \%$ of the final CRP sample was taking medications with potentially anti-inflammatory effects. To investigate whether their inclusion could have affected results, we compared associations between unemployment and inflammatory markers in these participants and other participants.

\section{RESULTS}

Compared to those excluded, participants retained in final models were older and more likely to be male (both significant $\mathrm{p}<0.001)$. The original and final analytic samples are compared in table 1. Age-adjusted associations of inflammatory markers with covariates are shown in online supplementary appendix D.

Unemployment was higher among Scottish participants than English participants at $2.6 \%$, compared to $2.1 \%$ in the final CRP sample (table 2). Within England, it was lowest in the Southwest at $1.4 \%$.

\section{Unemployment and inflammation}

Across the whole sample, log-transformed CRP, log-transformed fibrinogen and odds of CRP $>3 \mathrm{mg} / \mathrm{L}$ were significantly raised for unemployed, compared to employed participants (table 3). Effects were robust to adjustment for age, gender, socioeconomic position, long-term illness, GHQ-12 score and health behaviours. For all three markers, attenuation occurred with adjustment for SEP (table 3) but additional adjustment made little difference.

Significant interactions were found for age band and country, although not for gender. Age-stratified and country-stratified analyses were conducted to investigate further. Within England, interactions of unemployment and government office region were tested for with the Southeast (the largest group) as baseline.

\section{Stratification by age band, country and region}

Associations of unemployment with CRP and fibrinogen were significantly stronger for participants aged 48-64, compared to those aged 16-31 (interaction $p=0.004$ and $p=0.001$, respectively). Stratification by age band (table 4) showed that 
associations with all three markers were strong for those aged 48 and over, but non-significant in the younger groups.

Associations with CRP and fibrinogen were considerably stronger for Scottish participants (interactions $\mathrm{p}<0.001$ and $\mathrm{p}=0.007$ ). Stratification by country (table 5 ) showed that among English participants, only odds of CRP $>3 \mathrm{mg} / \mathrm{L}$ was significantly raised for unemployed participants after full adjustment but in Scotland, associations with all three measures of inflammation were robust. Within England, there were significant regional interactions for CRP and fibrinogen (interactions $p=0.03$ and $p=0.02$ ). This was driven by differences in the Southwest, where associations of all three inflammatory markers with unemployment were found to be negative (table 5).

\section{Sensitivity analyses}

Age-adjusted, gender-adjusted, country-adjusted and yearadjusted associations between unemployment and inflammatory markers did not differ between participants lacking covariate data and other participants, indicating their exclusion had not produced bias. Associations did not differ between participants taking anti-inflammatory medicines other participants, indicating their inclusion had not produced bias.

Since the years of data collection differed between the two countries, we considered whether country differences might reflect secular changes in associations of unemployment and health due to the onset of the recession. Analyses were re-run and restricted to 2003, a year well before the recession when large numbers of observations were taken in both countries, but significant country interactions remained for both CRP $(\mathrm{p}=0.01)$ and fibrinogen $(\mathrm{p}=0.05)$.

To explore whether country/regional differences were due to climate, English observations were stratified into latitudinal bands: The North West, North East and Yorkshire, the Midlands and East Anglia and London and the South. No latitude effect was observed.

In both countries (see online supplementary appendices B and $\mathrm{C}$ ), attenuation occurred with adjustment for SEP on all measures of inflammation. In contrast, additional adjustment for long-term illness made no difference in either country. Adjustment for health behaviours produced modest attenuation in Scotland, but not for England.

\section{DISCUSSION}

\section{Unemployment and inflammation}

In a large data set representing working-age people in England and Scotland, we found elevations in CRP and fibrinogen among unemployed men and women, compared to their employed counterparts. Results were robust to adjustment for pre-existing illness, social position, health behaviours and symptoms of depression/anxiety. This suggests unemployment is linked to inflammation via pathways independent of these factors and that inflammation may help explain the increased morbidity and mortality repeatedly observed in this group.

Our findings accord with research linking inflammation to social stressors, including bereavement ${ }^{27}$ and caregiving ${ }^{28}$ and disadvantaged socioeconomic position. ${ }^{29} 30$ To our knowledge, two studies have explored associations between unemployment and inflammation. Both were small, with sample sizes of $225^{31}$ and $1227,{ }^{32}$ and neither carried out in a UK population. Both report that inflammatory markers (CRP and/or Interleukin-6) were raised in unemployed participants compared to working counterparts. Our findings serve to confirm and extend these findings using data from large scale, nationally representative UK studies.
Our results do not support a model whereby the poor health of the unemployed can be explained by direct selection due to poor health. However, in both countries, substantial attenuation occurred with adjustment for SEP, supporting indirect selection by socioeconomic position.

While unemployment is associated with adverse health behaviours, ${ }^{33}$ in our study this did not explain the association of unemployment with raised inflammatory markers. Modest attenuation with adjustment for smoking, drinking and BMI was observed in Scotland, but not in England. This may reflect inaccuracies in measurement of tobacco and alcohol consumption in large-scale health surveys, limiting how effectively these factors can be controlled for. Alternatively, results may support the idea that the relationship of unemployment with health behaviours may itself vary by context. ${ }^{34}$

Associations were largely independent of psychological distress as measured by the GHQ-12. Measurement of psychological distress may not have been optimal in our analyses, since there is more evidence that inflammation is associated with depression than anxiety and the GHQ-12 may be a relatively poor measure of depression. Disadvantaged groups may also tend to under-report symptoms of minor psychiatric disorder as measured by the GHQ, ${ }^{35}$ potentially leading to discrepancies in the accuracy of measurements for biomarkers and psychiatric symptoms.

\section{Age and country/regional effects}

The age modification observed could reflect unemployment being more stressful for older jobseekers, for instance due to outdated skills, or real or perceived job discrimination. ${ }^{5}$ Alternatively, it could reflect accumulation of exposure over the life course. There is substantial evidence that unemployment spells cluster longitudinally within individuals, due to loss of skills or impact on perceived employability. ${ }^{36} 37$ There is also evidence that effects of unemployment on inflammation are lasting and could act additively over time. ${ }^{32}$ Hence, late-career unemployment may be acting as a marker for longer term unemployment and/or more past unemployment, with plausibly greater effects on inflammation.

It is unclear what is driving the country/regional modifications. Sensitivity analyses allowed us to discount differential medication use by country, proximity of data collection to the recession and latitude as explanations. Furthermore, country differences are not consistent with differential selection effects due to variation in background unemployment rate. 'Direct selection'-the idea that poor health of the unemployed can be largely explained by selection into unemployment of the unhealthy, and/or selection of the healthier unemployed back into employment-predicts weaker associations of unemployment and ill-health in times and places when unemployment is higher. Against a high background unemployment rate, job loss should be less discriminating, selection minimised and the unemployed more 'normal' as a result. ${ }^{2}$ Since unemployment benefit rates are determined by central UK government, country effects are unlikely to stem from differential financial impacts of unemployment. Hence, if the differences are not due to any of these processes and persist after full adjustment, results may implicate a genuinely greater impact of unemployment in Scotland via alternative pathways, such as psychosocial stress.

While selection predicts stronger associations of unemployment and ill-health against a low background unemployment rate, there are also theoretical reasons to expect the opposite. It has been suggested that unemployment may be a more stressful experience, with worse effects on health where unemployment 
Table 1 Descriptive characteristics of the sample

\begin{tabular}{|c|c|c|c|}
\hline & $\begin{array}{l}\text { Initial sample } \\
\text { (16-64, } \\
\text { targeted for } \\
\text { blood sample) } \\
\mathrm{N}=49385\end{array}$ & $\begin{array}{l}\text { Final } \\
\text { analytic } \\
\text { sample for } \\
\text { CRP } \\
N=23025\end{array}$ & $\begin{array}{l}\text { Final analytic } \\
\text { sample for } \\
\text { fibrinogen } \\
N=20724\end{array}$ \\
\hline \multicolumn{4}{|l|}{ Age } \\
\hline \multirow[t]{2}{*}{ Mean (SD) } & $41.2(13.4)$ & $43.1(12.4)$ & $42.3(12.2)$ \\
\hline & $\%$ & $\%$ & $\%$ \\
\hline \multicolumn{4}{|l|}{ Age group } \\
\hline 16-31 (early career) & 26.6 & 20.1 & 21.3 \\
\hline 32-47 (mid-career) & 37.7 & 40.4 & 42.2 \\
\hline 48-64 (late career) & 35.7 & 39.5 & 36.5 \\
\hline \multicolumn{4}{|l|}{ Gender } \\
\hline Men & 45.0 & 47.3 & 47.1 \\
\hline Women & 55.0 & 52.7 & 52.9 \\
\hline \multicolumn{4}{|l|}{$\begin{array}{l}\text { Occupational social class } \\
\text { (RGSC) from current or } \\
\text { past employment }\end{array}$} \\
\hline i—professional & 4.8 & 5.7 & 5.8 \\
\hline ii-managerial-technical & 28.4 & 32.2 & 32.2 \\
\hline $\begin{array}{l}\text { iii-nm—skilled } \\
\text { non-manual }\end{array}$ & 22.7 & 23.1 & 23.3 \\
\hline iii-m—skilled manual & 16.7 & 17.8 & 17.7 \\
\hline iv—semiskilled manual & 16.8 & 16.5 & 16.5 \\
\hline$v$ —unskilled manual & 5.1 & 4.8 & 4.6 \\
\hline Missing & 5.5 & & \\
\hline \multicolumn{4}{|l|}{ Housing tenure } \\
\hline Owns outright & 20.1 & 22.1 & 20.9 \\
\hline $\begin{array}{l}\text { Buying with a } \\
\text { mortgage/loan }\end{array}$ & 52.5 & 56.3 & 57.5 \\
\hline Renting/other & 27.1 & 21.6 & 21.6 \\
\hline Missing & 0.3 & & \\
\hline \multicolumn{4}{|l|}{ Economic status } \\
\hline In paid employment & 68.0 & 75.2 & 76.5 \\
\hline $\begin{array}{l}\text { Unemployed, seeking } \\
\text { work }\end{array}$ & 2.9 & 2.2 & 2.2 \\
\hline Sick or disabled & 6.2 & 4.3 & 3.6 \\
\hline $\begin{array}{l}\text { Other economically } \\
\text { inactive }\end{array}$ & 22.7 & 18.3 & 17.7 \\
\hline Missing & 0.3 & & \\
\hline \multicolumn{4}{|l|}{ Cigarette smoking } \\
\hline Never smoker & 45.2 & 45.0 & 45.5 \\
\hline Ex-smoker & 25.9 & 28.9 & 28.2 \\
\hline Current, <10/day & 7.6 & 7.1 & 7.1 \\
\hline Current, 10-19/day & 11.4 & 10.6 & 10.7 \\
\hline Current, 20+/day & 8.8 & 8.4 & 8.5 \\
\hline Missing & 1.0 & & \\
\hline \multicolumn{4}{|l|}{$\begin{array}{l}\text { Drinking frequency in past } \\
12 \text { months }\end{array}$} \\
\hline $\begin{array}{l}\text { Every couple months or } \\
\text { less }\end{array}$ & 12.7 & 11.5 & 11.3 \\
\hline Once or twice/month & 13.2 & 12.8 & 12.9 \\
\hline Once or twice/week & 31.2 & 32.5 & 33.0 \\
\hline 3 or 4 days/week & 15.8 & 18.0 & 18.2 \\
\hline 5 days/week or more & 16.4 & 19.0 & 18.8 \\
\hline $\begin{array}{l}\text { Not in past } 12 \text { months/ } \\
\text { non-drinker }\end{array}$ & 10.0 & 6.2 & 5.9 \\
\hline Missing & 0.7 & & \\
\hline \multicolumn{4}{|l|}{ BMI categories } \\
\hline$<18.5$ & 1.5 & 1.1 & 1.1 \\
\hline $18.5-24.99$ & 34.4 & 38.1 & 39.4 \\
\hline 25-29.99 & 32.9 & 39.8 & 39.9 \\
\hline
\end{tabular}

Table 1 Continued

\begin{tabular}{|c|c|c|c|}
\hline & $\begin{array}{l}\text { Initial sample } \\
(16-64, \\
\text { targeted for } \\
\text { blood sample) } \\
\mathrm{N}=49385\end{array}$ & $\begin{array}{l}\text { Final } \\
\text { analytic } \\
\text { sample for } \\
\text { CRP } \\
N=23025\end{array}$ & $\begin{array}{l}\text { Final analytic } \\
\text { sample for } \\
\text { fibrinogen } \\
N=20724\end{array}$ \\
\hline $30+$ & 19.9 & 21.0 & 19.6 \\
\hline Missing & 11.3 & & \\
\hline \multicolumn{4}{|l|}{ Limiting long-term illness? } \\
\hline No long-term illness & 61.5 & 61.7 & 64.3 \\
\hline $\begin{array}{l}\text { Limiting long-term } \\
\text { illness }\end{array}$ & 21.2 & 19.6 & 18.1 \\
\hline $\begin{array}{l}\text { Non-limiting long-term } \\
\text { illness }\end{array}$ & 17.2 & 18.7 & 17.6 \\
\hline Missing & 0.1 & & \\
\hline \multicolumn{4}{|l|}{ GHQ-12 score } \\
\hline $0-3$ & 80.3 & 86.3 & 86.6 \\
\hline $4+$ & 14.1 & 13.7 & 13.4 \\
\hline Missing & 5.6 & & \\
\hline \multicolumn{4}{|l|}{ Survey } \\
\hline HSE 1998 & 25.6 & 30.6 & 31.4 \\
\hline HSE 1999 & 0.6 & 0.7 & 0.7 \\
\hline HSE 2003 & 23.5 & 23.9 & 23.9 \\
\hline HSE 2006 & 22.0 & 21.1 & 20.7 \\
\hline HSE 2009 & 7.1 & 6.3 & 6.2 \\
\hline SHeS 2003 & 12.6 & 10.9 & 10.7 \\
\hline SHeS 2008 & 2.8 & 2.2 & 2.1 \\
\hline SHeS 2009 & 2.9 & 2.3 & 2.1 \\
\hline SHeS 2010 & 2.9 & 2.2 & 2.1 \\
\hline \multicolumn{4}{|l|}{ Government office region } \\
\hline Scotland & 21.2 & 17.5 & 17.0 \\
\hline Northeast & 4.5 & 4.6 & 4.7 \\
\hline Northwest & 11.3 & 11.9 & 11.9 \\
\hline $\begin{array}{l}\text { Yorkshire and } \\
\text { Humberside }\end{array}$ & 8.2 & 9.0 & 8.9 \\
\hline West Midlands & 8.4 & 8.7 & 8.9 \\
\hline East Midlands & 7.4 & 7.9 & 7.8 \\
\hline East Anglia & 8.8 & 9.1 & 9.1 \\
\hline London & 10.1 & 8.4 & 8.4 \\
\hline Southeast & 12.5 & 14.4 & 14.7 \\
\hline Southwest & 7.7 & 8.5 & 8.5 \\
\hline \multicolumn{4}{|l|}{$\begin{array}{l}\text { Takes medications which } \\
\text { could affect inflammation }\end{array}$} \\
\hline Yes & 10.5 & 12.7 & 7.1 \\
\hline No & 89.5 & 87.3 & 92.9 \\
\hline
\end{tabular}

CRP, C reactive protein; GHQ-12, General Health Questionnaire; HSE, Health Survey for England; SHeS, Scottish Health Survey.

is high because jobseekers will perceive prospects for re-employment as worse. ${ }^{38}$ This could produce stronger associations of unemployment and ill-health, despite weaker selection effects.

A final possibility is that country and regional differences may again reflect life course accumulation processes. If unemployment was more widespread in Scotland at the time of data collection and had been during much of these participants' working lives, then it is likely that unemployed Scottish participants will have been unemployed for longer than their counterparts elsewhere or accumulated more lifetime unemployment, with plausibly greater effects on inflammation. Indeed, this explanation is supported by the stronger associations observed for older participants, since differences stemming from accumulation processes would be expected to emerge later in life. 
Table 2 Distribution of employment status (\%) in final analytic sample (CRP analyses), by country/region

\begin{tabular}{lccc}
\hline & $\begin{array}{l}\text { All English } \\
\text { Surveys }\end{array}$ & $\begin{array}{l}\text { All Scottish } \\
\text { Surveys }\end{array}$ & $\begin{array}{l}\text { England: } \\
\text { Southwest only }\end{array}$ \\
\hline Paid employment & 75.6 & 73.3 & 74.7 \\
Unemployed & 2.1 & 2.6 & 1.4 \\
Sick/disabled & 4.0 & 5.8 & 3.1 \\
Other economically inactive & 18.4 & 18.4 & 20.7 \\
Total N & 18997 & 4028 & 1959 \\
\hline
\end{tabular}

CRP, C reactive protein.

While this cannot be tested within this cross-sectional data set, support comes from other UK data sources for this period. An analysis of unemployment duration between 1991 and 2006 using the British Household Panel Survey ${ }^{39}$ found probability of re-employment during follow-up was lower in Scotland than in every English region (0.655, compared to the South East).

The negative effects in the South West require a different explanation. Unemployed participants in the South West did not appear different in terms of demographics or health behaviours, but this region had the least unemployment, in accordance with Labour Force Survey data from this period. It is, therefore, likely that these participants will have been unemployed for less time than their counterparts elsewhere, perhaps with better perceptions of re-employment prospects playing an additional protective role. However, these factors cannot explain why inflammatory markers were actually lower for the unemployed compared to employed participants in this region.

Given the small sample sizes in regionally-stratified models, negative effects in the South West could be type 1 errors. Alternatively, differences in three-way selection between the employed, unemployed and economically inactive could be involved. For people with sufficient health problems to claim sickness/disability benefits, the financial incentive to exit the labour market altogether is considerably greater for those who are unemployed than employed, and people do appear to follow these incentives. ${ }^{40}$ Such differential labour market exit would mean that, all else equal, the unemployed should be more selected for good health than the employed. Of course, other processes-such as selection of healthy jobseekers back into employment plus any negative causal influences of unemployment on health-would act in the opposite direction, potentially obscuring effects of differential labour market exit. However, in a context of very low unemployment, these effects could plausibly come to the fore, possibly accounting for the negative associations in the South West. If so, effects reported for Scotland, and England overall, should be considered underestimates.

This analysis had several advantages; our sample was much larger than the two previous studies, and contained both men

Table 3 Associations of current unemployment with inflammatory markers: whole-sample analysis

\begin{tabular}{|c|c|c|c|c|c|c|c|c|c|}
\hline \multirow[b]{2}{*}{ Adjustment level } & \multicolumn{3}{|c|}{$\begin{array}{l}\text { CRP (mg/L, log-transformed) } \\
\mathrm{N}=23025\end{array}$} & \multicolumn{3}{|c|}{$\begin{array}{l}\text { Fibrinogen ( } g / L \text {, log-transformed) } \\
\mathrm{N}=20724\end{array}$} & \multicolumn{3}{|c|}{$\begin{array}{l}\mathrm{CRP}>3 \mathrm{mg} / \mathrm{L} \\
\mathrm{N}=23025\end{array}$} \\
\hline & Coefficient & $\mathrm{Cl}$ & $\mathrm{p}$ Value & Coefficient & $\mathrm{Cl}$ & $\mathrm{p}$ Value & OR & $\mathrm{Cl}$ & p Value \\
\hline \multicolumn{10}{|l|}{ Age, gender, country, year } \\
\hline In paid employment & Ref. & & & Ref. & & & 1.0 & & \\
\hline Unemployed & 0.22 & 0.13 to 0.32 & $<0.001$ & 0.05 & 0.03 to 0.07 & $<0.001$ & 1.66 & 1.35 to 2.03 & $<0.001$ \\
\hline Sick/disabled & 0.42 & 0.35 to 0.49 & $<0.001$ & 0.07 & 0.06 to 0.09 & $<0.001$ & 2.33 & 2.04 to 2.66 & $<0.001$ \\
\hline Other economically inactive & 0.05 & 0.01 to 0.08 & 0.01 & 0.02 & 0.01 to 0.03 & $<0.001$ & 1.21 & 1.12 to 1.31 & $<0.001$ \\
\hline \multicolumn{10}{|c|}{$\begin{array}{l}\text { Age, gender, country, year and socioeconomic } \\
\text { position }\end{array}$} \\
\hline In paid employment & Ref. & & & & & & & & \\
\hline Unemployed & 0.16 & 0.07 to 0.26 & 0.001 & 0.03 & 0.01 to 0.05 & 0.001 & 1.48 & 1.20 to 1.81 & $<0.001$ \\
\hline Sick/disabled & 0.33 & 0.26 to 0.40 & $<0.001$ & 0.05 & 0.03 to 0.07 & $<0.001$ & 1.97 & 1.71 to 2.26 & $<0.001$ \\
\hline Other economically inactive & 0.04 & -0.00 to 0.07 & 0.07 & 0.01 & 0.00 to 0.02 & 0.01 & 1.18 & 1.08 to 1.27 & $<0.001$ \\
\hline \multicolumn{10}{|c|}{$\begin{array}{l}\text { Age, gender, country, year, socioeconomic } \\
\text { position and long-term illness }\end{array}$} \\
\hline In paid employment & Ref. & & & & & & & & \\
\hline Unemployed & 0.15 & 0.06 to 0.24 & 0.002 & 0.03 & 0.01 to 0.05 & 0.001 & 1.45 & 1.18 to 1.78 & $<0.001$ \\
\hline Sick/disabled & 0.21 & 0.14 to 0.29 & $<0.001$ & 0.04 & 0.02 to 0.06 & $<0.001$ & 1.60 & 1.37 to 1.85 & $<0.001$ \\
\hline Other economically inactive & 0.02 & -0.01 to 0.06 & 0.21 & 0.01 & 0.00 to 0.02 & 0.02 & 1.15 & 1.06 to 1.25 & 0.001 \\
\hline \multicolumn{10}{|c|}{$\begin{array}{l}\text { Age, gender, country, year, socioeconomic } \\
\text { position, long-term illness and health behaviours }\end{array}$} \\
\hline In paid employment & Ref. & & & & & & & & \\
\hline Unemployed & 0.14 & 0.06 to 0.23 & 0.001 & 0.02 & 0.00 to 0.04 & 0.02 & 1.44 & 1.16 to 1.80 & 0.001 \\
\hline Sick/disabled & 0.18 & 0.11 to 0.25 & $<0.001$ & 0.03 & 0.01 to 0.04 & 0.003 & 1.58 & 1.35 to 1.85 & $<0.001$ \\
\hline Other economically inactive & 0.05 & 0.01 to 0.08 & 0.01 & 0.01 & 0.00 to 0.02 & 0.003 & 1.20 & 1.10 to 1.31 & $<0.001$ \\
\hline \multicolumn{10}{|c|}{$\begin{array}{l}\text { Age, gender, country, year, socioeconomic position, } \\
\text { long-term illness, health behaviours and GHQ-12 }\end{array}$} \\
\hline In paid employment & Ref. & & & & & & & & \\
\hline Unemployed & 0.14 & 0.06 to 0.23 & 0.001 & 0.02 & 0.00 to 0.04 & 0.02 & 1.43 & 1.15 to 1.78 & 0.001 \\
\hline Sick/disabled & 0.18 & 0.11 to 0.25 & $<0.001$ & 0.03 & 0.01 to 0.04 & 0.002 & 1.54 & 1.31 to 1.82 & $<0.001$ \\
\hline Other economically inactive & 0.05 & 0.01 to 0.08 & 0.01 & 0.01 & 0.00 to 0.02 & 0.003 & 1.20 & 1.10 to 1.30 & $<0.001$ \\
\hline
\end{tabular}


Table 4 Fully adjusted* associations of current unemployment with inflammatory markers in whole sample, stratified by age group

\begin{tabular}{|c|c|c|c|c|c|}
\hline Age band & Coefficient/OR & $\mathrm{Cl}$ & $\mathrm{p}$ Value & N (unemployed) & $\mathrm{N}$ (total) \\
\hline \multicolumn{6}{|l|}{$16-31$} \\
\hline Log CRP & 0.10 & -0.06 to 0.26 & 0.21 & 188 & 4621 \\
\hline Log fibrinogen & 0.01 & -0.02 to 0.05 & 0.39 & 177 & 4411 \\
\hline CRP, dichotomised & 1.29 & 0.86 to 1.95 & 0.22 & 188 & 4621 \\
\hline \multicolumn{6}{|l|}{$32-47$} \\
\hline Log CRP & 0.07 & -0.07 to 0.21 & 0.34 & 171 & 9309 \\
\hline Log fibrinogen & 0.00 & -0.03 to 0.03 & 0.99 & 165 & 8747 \\
\hline CRP, dichotomised & 1.35 & 0.91 to 2.00 & 0.14 & 171 & 9309 \\
\hline \multicolumn{6}{|l|}{$48-64$} \\
\hline Log CRP & 0.28 & 0.13 to 0.42 & $<0.001$ & 146 & 9095 \\
\hline Log fibrinogen & 0.07 & 0.04 to 0.10 & $<0.001$ & 120 & 7566 \\
\hline CRP, dichotomised & 1.57 & 1.08 to 2.27 & 0.02 & 146 & 9095 \\
\hline
\end{tabular}

Table 5 Fully adjusted* associations of current unemployment with inflammatory markers, all age groups, stratified by country/region

\begin{tabular}{|c|c|c|c|c|c|}
\hline & Coefficient/OR & $\mathrm{Cl}$ & $\mathrm{p}$ Value & N (unemployed) & N (Total) \\
\hline \multicolumn{6}{|l|}{ Scotland } \\
\hline Log CRP & 0.43 & 0.24 to 0.62 & $<0.001$ & 102 & 4038 \\
\hline Log fibrinogen & 0.07 & 0.03 to 0.12 & $<0.001$ & 95 & 3522 \\
\hline CRP, dichotomised & 1.98 & 1.24 to 3.17 & 0.01 & 102 & 4038 \\
\hline \multicolumn{6}{|l|}{ England } \\
\hline Log CRP & 0.07 & -0.03 to 0.16 & 0.18 & 399 & 18997 \\
\hline Log fibrinogen & 0.01 & -0.01 to 0.03 & 0.37 & 365 & 17202 \\
\hline CRP, dichotomised & 1.29 & 1.00 to 1.66 & 0.046 & 399 & 18997 \\
\hline \multicolumn{6}{|c|}{ ENGLAND—Southwest only } \\
\hline Log CRP & -0.33 & -0.60 to -0.06 & 0.02 & 28 & 1959 \\
\hline Log fibrinogen & -0.07 & -0.13 to -0.02 & 0.007 & 27 & 1763 \\
\hline CRP, dichotomised & 0.53 & 0.19 to 1.47 & 0.22 & 28 & 1959 \\
\hline
\end{tabular}

and women from across the working-age range, increasing generalisability of results. By considering a wide range of potential confounders and mediators, we were able to explore confounding by socioeconomic position, by pre-existing illness and the role of health behaviours. Participants who were temporarily sick during a spell of unemployment were excluded, leading to conservative estimates.

This analysis has three main limitations. The first concerns loss of data between those targeted for a blood sample, and the usable CRP and fibrinogen measurements actually obtained; resultant bias cannot be ruled out. Second, comparatively few unemployed women in the sample meant gender modifications could not be fully explored. Third, analysis of current unemployment in the context of life histories was not possible. This would have allowed further exploration of effect modifications by age and region.

\section{CONCLUSIONS}

This analysis found robust elevations in CRP, fibrinogen and odds of CRP $>3 \mathrm{mg} / \mathrm{L}$ among English and Scottish unemployed men and women compared to their employed counterparts, but strength of effects varied considerably by both age and country/ region, suggesting the relationship of unemployment with inflammation may be strongly influenced by environmental or contextual factors. Alternatively, if these differences reflect life course accumulation processes, they may indicate long-term or repeated unemployment as especially damaging to aspects of health related to inflammation.

\section{What is already known on this subject}

- Systemic inflammation is increasingly implicated as a mediating factor relating stress to morbidity and mortality.

- Both morbidity and mortality are elevated during unemployment, but questions remain regarding the direction of causation and mediating mechanisms involved.

- Two small-scale studies have reported elevated inflammatory markers in unemployed participants, consistent with an impact of unemployment on health via psychosocial stress. 


\section{What this study adds}

- We confirm and extend these findings using data from two large-scale, nationally representative studies, and explore this association in a UK context, for the first time.

- While current unemployment was robustly associated with elevated inflammatory markers, effect modifications by both age and region suggest the relationship may be strongly influenced by contextual factors and/or accumulation processes.

Funding $\mathrm{AH}$ is supported by an ESRC PhD Studentship. MK time on this manuscript was partially supported by the Economic and Social Research Council (RES-596-28-0001). AM time on this manuscript was supported by European Research Council Starting Grant scheme, Grant Agreement №281957. MB is an Emeritus Professor at UCL.

\section{Competing interests None.}

Provenance and peer review Not commissioned; externally peer reviewed.

Data sharing statement This analysis was entirely conducted on data publicly available from the UK Data Service.

Open Access This is an Open Access article distributed in accordance with the terms of the Creative Commons Attribution (CC BY 4.0) license, which permits others to distribute, remix, adapt and build upon this work, for commercial use, provided the original work is properly cited. See: http://creativecommons.org/ licenses/by/4.0/

\section{REFERENCES}

1 Roelfs DJ, Shor E, Davidson KW, et al. Losing life and livelihood: a systematic review and meta-analysis of unemployment and all-cause mortality. Soc Sci Med 2011;72:840-54.

2 Moser KA, Goldblatt PO, Fox AJ, et al. Unemployment and mortality - comparison of the 1971 and 1981 longitudinal study census samples. Br Med I (Clin Res Ed) 1987;294:86-90.

3 Martikainen PT, Valkonen T. Excess mortality of unemployed men and women during a period of rapidly increasing unemployment. Lancet 1996;348:909-12

4 Murphy GC, Athanasou JA. The effect of unemployment on mental health. J Occup Organ Psychol 1999;72:83-99.

5 McKee-Ryan FM, Song ZL, Wanberg CR, et al. Psychological and physical well-being during unemployment: a meta-analytic study. J Appl Psychol 2005;90:53-76.

6 Paul KI, Moser K. Unemployment impairs mental health: meta-analyses. J Vocational Behav 2009;74:264-82.

7 Warr P. Work, unemployment and mental health. New York: Oxford University Press, 1987.

8 Steel DM, Whitehead AS. The major acute-phase reactants-C-reactive protein, serum amyloid-P component and serum amyloid-A protein. Immunol Today 1994; 15:81-8

9 Yudkin JS, Kumari M, Humphries SE, et al. Inflammation, obesity, stress and coronary heart disease: is interleukin-6 the link? Atherosclerosis 2000;148:209-14.

10 Dowlati Y, Herrmann N, Swardfager W, et al. A meta-analysis of cytokines in major depression. Biol Psychiatry 2010;67:446-57.

11 Mindell J, Biddulph JP, Hirani V, et al. Cohort profile: the Health Survey for England. Int J Epidemiol 2012;41:1585-93.

12 Gray L, Batty GD, Craig P, et al. Cohort profile: the Scottish Health Surveys Cohort: linkage of study participants to routinely collected records for mortality, hospital discharge, cancer and offspring birth characteristics in three nationwide studies. Int J Epidemiol 2010;39:345-50.

13 Corbett J, Given L, Gray L, et al. The Scottish Health Survey 2008, Volume 2: Technical Report. Edinburgh: The Scottish Government, 2009.

14 Bradshaw P, Bromley C, Corbett J, et al. The Scottish Health Survey 2011 Volume 3: Technical report. The Scottish Government, 2012.
15 Pearson TA, Mensah GA, Alexander RW, et al. Markers of inflammation and cardiovascular disease application to clinical and public health practice-A statement for healthcare professionals from the centers for disease control and prevention and the American Heart Association. Circulation 2003;107: 499-511.

16 ILO. Resolution concerning statistics of the economically active population, employment, unemployment and underemployment, adopted by the Thirteenth International Conference of Labour Statisticians. Geneva: International Labour Organization, 1982

17 Ingle L, Carroll S, Stamatakis E, et al. Benefit of adding lifestyle-related risk factors for prediction of cardiovascular death among cardiac patients. Int I Cardiol 2013;163:196-200.

18 Bajekal M, Boreham R, Brookes M, et al. Health Survey for England: cardivascular disease 1998, Volume 2: methodology \& documentation. Department of Health, 1999.

19 Blake M, Deverill C, Prescott A, et al. The Health Survey for England 2003, Volume 3: methodology and documentation. London: Joint Health Surveys Unit, National Centre for Social Research, 2004.

20 Bajekal M, Becher H, Boreham R, et al. Health Survey for England: the health of minority ethnic groups 1999, Volume 2: methodology \& documentation. London: Joint Health Surveys Unit, National Centre for Social Research, 2001.

21 Bromley C, Chaudhury M, Craig R, et al. The Scottish Health Survey 2003, Volume 4: Technical Report. Edinburgh: The Scottish Government, 2005.

22 Corbett J, Dobbie F, Doig M, et al. The Scottish Health Survey 2009 Volume 2: Technical Report. Edinburgh: The Scottish Government, 2010.

23 Aresu M, Chaudhury M, Diment E, et al. Health Survey for England 2009, Volume 2: methods and documentation. Joint Health Surveys Unit, National Centre for Social Research, 2011.

24 Bromley C, Corbett J, Day J, et al. The Scottish Health Survey 2010 Volume 2: Technical Report. Edinburgh: The Scottish Government, 2011.

25 Ali A, Becker E, Chaudhury M, et al. Health Survey for England 2006 Volume 3: methodology and documentation. London: The Information Centre, 2008.

26 Ridker PM. C-reactive protein-a simple test to help predict risk of heart attack and stroke. Circulation 2003;108:E81-5.

27 Buckley T, Morel-Kopp MC, Ward C, et al. Inflammatory and thrombotic changes in early bereavement: a prospective evaluation. Eur I Prev Cardiol 2012;19: $1145-52$.

28 Kiecolt-Glaser JK, Preacher KJ, MacCallum RC, et al. Chronic stress and age-related increases in the proinflammatory cytokine IL-6. Proc Natl Acad Sci USA 2003;100:9090-5.

29 Gimeno D, Ferrie JE, Elovainio $\mathrm{M}$, et al. When do social inequalities in C-reactive protein start? A life course perspective from conception to adulthood in the Cardiovascular Risk in Young Finns Study. Int J Epidemiol 2008;37:290-8.

30 McDade TW, Lindau ST, Wroblewski K. Predictors of C-reactive protein in the national social life, health, and aging project. J Gerontol B Psychol Sci Soc Sci 2011;66:129-36

31 Hintikka J, Lehto SM, Niskanen L, et al. Unemployment and ill health: a connection through inflammation? BMC Public Health 2009:9:410.

32 Janicki-Deverts D, Cohen S, Matthews KA, et al. History of unemployment predicts future elevations in C-reactive protein among male participants in the Coronary Artery Risk Development in Young Adults (CARDIA) study. Ann Behav Med 2008;36:176-85.

33 Wadsworth ME, Montgomery SM, Bartley MJ. The persisting effect of unemployment on health and social well-being in men early in working life. Soc Sci Med 1999:48:1491-9.

34 Bolton K, Rodriguez E. Smoking, drinking and body weight after re-employment: does unemployment experience and compensation make a difference? BMC Public Health 2009;9:77.

35 Stansfeld SA, Marmot MG. Social-class and minor psychiatric-disorder in British Civil-Servants—a validated screening survey using the General Health Questionnaire. Psychol Med 1992;22:739-49.

36 Gregg P. The impact of youth unemployment on adult unemployment in the NCDS. Econ J 2001;111:F626-F53.

37 Arulampalam W, Booth AL, Taylor MP. Unemployment persistence. Oxf Econ Pap New Ser 2000;52:24-50.

38 Turner JB. Economic context and the health-effects of unemployment. J Health Soc Behav 1995;36:213-29.

39 Long K. Unemployment durations: evidence from the British Household Panel Survey. Econ Lab Mark Rev 2009;3:48-54.

40 Beatty C, Fothergill S. The diversion from 'unemployment' to 'sickness' across British regions and districts. Reg Stud 2005;39:837-54. 